Relations industrielles

Industrial Relations

\title{
Statistics and Information
}

Volume 5, numéro 5, février 1950

URI : https://id.erudit.org/iderudit/1023332ar

DOI : https://doi.org/10.7202/1023332ar

Aller au sommaire du numéro

Éditeur(s)

Département des relations industrielles de l’Université Laval

ISSN

0034-379X (imprimé)

1703-8138 (numérique)

Découvrir la revue

Citer cet article

(1950). Statistics and Information. Relations industrielles / Industrial Relations, 5(5), 50-50. https://doi.org/10.7202/1023332ar

Tous droits réservés (C Département des relations industrielles de l’Université Laval, 1950
Ce document est protégé par la loi sur le droit d'auteur. L'utilisation des services d'Érudit (y compris la reproduction) est assujettie à sa politique d'utilisation que vous pouvez consulter en ligne.

https://apropos.erudit.org/fr/usagers/politique-dutilisation/ 
sociale »; François Perroux, director of the «Institut des sciences économiques appliquées ».

The subscription price for each of these Reviews is 1,600 francs. Those who are already subscribers to
«DROIT SOCIAL 》 benefit from a reduction of 200 francs for the subscription to \&SECURITE SOCIALE ET PRESTATIONS FAMILIALES 》.

Write: Librairie sociale et économique, 3, rue Souflet, Paris Ve.

STATISTICS AND INFORMATION

AWARDS BETWEEN NOVEMBER 1 AND 30, 1949

Employer

\begin{tabular}{|c|c}
$\begin{array}{c}\text { Affiliation of the } \\
\text { Labour Group }\end{array}$ & $\begin{array}{c}\text { Date of the } \\
\text { Award }\end{array}$ \\
\hline CGL & $4-11-49$ \\
AFL & $10-11-49$ \\
TLC & $11-11-49$ \\
CGL & $9-11-49$ \\
Ind. & $14-11-49$ \\
CGL & $17-11-49$ \\
CCCL & $15-11-49$ \\
Ind. & $30-11-49$ \\
CGL & $19-11-49$
\end{tabular}

S. Golstein.

Montreal Upholstering.

Dominion Tar \& Chemicals Co. Ltd.

City of Verdun - Firemen

City of Verdun - Policemen.

American Can Co..

Eastern Furniture Co.

St. Maurice Furniture Co. Ltd.

Bonner Leather Ltd \& Coyle Tanning Co.

ARBITRATION CASES ON NOVEMBER 30, 1949

\section{Employer}

M.E. Binz Co., Montmagny (grievances)

Bovry \& Staines Linoleum Ltd.

General Cigar Co. Ltd.

Asbestos Corporation Ltd.

Johnson's Co. Ltd.

Flinkote Mines

Singer Manufacturing Co.

Classon Knitting Mills Ltd.

Standard Shirt Co.

Fonderie Légaré

Quebec City Bakerie

Matthew Moody \& Sons Ltd.

Federal Electric

Manufacturing Co.

E.J. Maxwell Limited

Canadian Industries Limited (Brownsburg)

Drummondville and Victoriaville - Construction

City Furniture \& Frame Co.

Paramount Leather Goods

Empire Shirt, Louiseville

Atlas Bedding Ltd.

M.E. Binz Co. Ltd., Montmagny (renewal of agreement) Orange Crush \& Kik Co.

Hôtel-Dieu de Sherbrooke

Dubeau \& Frères, Joliette

J.-J. Joubert Ltée

A. Bélanger Ltée, Montmagny

Dominion Stores Ltd.

\section{Labour Group}

Syndicat national catholique du textile de Montmagny

Syndicat national des travailleurs de linoleum de Farnham

Tobacco Workers International Union, local 237 and 238

Syndicat national catholique des travailleurs de l'amiante d'Asbestos, de Johnson's Co. Ltd et de Flinkote Mines Ltd.

United Steel Workers of America, local 3764

Union des employés du vêtement de Sherbrooke

Union nationale du vêtement incorporée

Syndicat des employés de la Fonderie Légaré de Sherbrooke

United Steel Workers of America, local 4190

United Electrical Radio and Machine Workers of America, local 513

Association canadienne des travailleurs du bois, local 10

United Mine Workers of America, Canadian

Union internationale des remboureurs de l'Amérique du Nord, local 347

Union des ouvriers de la sacoche Syndicat national du vêtement de Louiseville Inc.

Union internationale des remboureurs de l'Amérique du Nord, local 302

Syndicat national catholique du textile de Montmagny

Transport Drivers Warehousemen and Helpers' Union, local 106

Association des employés du service hospitalier de Sherbrooke

Syndicat national catholique des travailleurs du bois de Joliette Inc.

Union ouvrière des employés de laiterie, local 973

Syndicat des travailleurs de la Fonderie de Montmagny Inc.

Retail Clerks International Association, local 486

\begin{tabular}{|c|c|}
\hline $\begin{array}{l}\text { Affiliation of } \\
\text { the Labour } \\
\text { Group }\end{array}$ & $\begin{array}{l}\text { President of the Council } \\
\text { of Arbitration }\end{array}$ \\
\hline CCCL & Justice Achille Pettigrew \\
\hline CCCL & Justice T.A. Fontaine \\
\hline AFL & Justice Jules Poisson \\
\hline CCCL & Justice Thomas Tremblay \\
\hline CIO & Jutice Armand Cloutier \\
\hline CCCL & G.D. Laviolette \\
\hline $\begin{array}{l}\text { CCCL } \\
\text { CCCL }\end{array}$ & $\begin{array}{l}\text { Justice Armand Cloutier } \\
\text { Justice Edouard Boisvert }\end{array}$ \\
\hline $\begin{array}{l}\text { CCCL } \\
\text { CGL } \\
\text { CIO } \\
\text { CIO }\end{array}$ & $\begin{array}{l}\text { Jean-Yves Gosselin } \\
\text { Justice Armand Cloutier } \\
\text { Me Ulric Laurencelle }\end{array}$ \\
\hline CLA Inc. & Me Roger Brassard \\
\hline CGL & Justice Alphonse Garon \\
\hline CCCL & Justice T.A. Fontaine \\
\hline AFL & Me André Montpetit \\
\hline $\begin{array}{l}\text { AFL } \\
\text { CCCL }\end{array}$ & $\begin{array}{l}\text { Justice T.A. Fontaine } \\
\text { Me Jean Gagné }\end{array}$ \\
\hline AFL & Justice Irénée Lagarde \\
\hline CCCL & Me Victor Trépanier \\
\hline AFL & Me André Montpetit \\
\hline CCCL & Justice Edouard Boisvert \\
\hline CCCL & Justice Guy Guilbault \\
\hline AFL & Justice Jules Poisson \\
\hline CCCL & Me Lucien Lortie \\
\hline AFL & Me André Montpetit \\
\hline
\end{tabular}

